\section{Access to special care dentistry, part 5. Safety}

\author{
A. Dougall ${ }^{1}$ and J. Fiske²
}

VERIFIABLE CPD PAPER
IN BRIEF

- Some people who look fit can have a hidden disability and/or complex medical condition which will impact on the delivery of dental care.

- Among such conditions are epilepsy, latex sensitivity, bisphosphonateassociated osteonecrosis of the jaw and bleeding disorders.

- The importance of careful medical history-taking to identify hidden conditions cannot be over-emphasised.

This article considers the delivery of efficient and effective dental services for patients whose disability and/or medical condition may not be obvious and which consequently can present a hidden challenge in the dental setting. Knowing that the patient has a particular condition, what its features are and how it impacts on dental treatment and oral health, and modifying treatment accordingly can minimise the risk of complications. The taking of a careful medical history that asks the right questions in a manner that encourages disclosure is key to highlighting hidden hazards and this article offers guidance for treating those patients who have epilepsy, latex sensitivity, acquired or inherited bleeding disorders and patients taking oral or intravenous bisphosphonates.

The NHS focus is on patient-centred care delivered safely in an environment that meets the needs of both patients and service providers In order to achieve this, it is important to remember that some people

\begin{tabular}{l} 
ACCESS TO SPECIAL \\
CARE DENTISTRY \\
\hline 1. Access \\
2. Communication \\
3. Consent \\
4. Education \\
5. Safety \\
6. Special care dentistry services for \\
adolescents and young adults \\
7. Special care dentistry services for \\
middle-aged people. Part 1 \\
8. Special care dentistry services for \\
middle-aged people. Part 2 \\
9. Special care dentistry services for \\
older people
\end{tabular}

\footnotetext{
'Lecturer and Consultant for Medically Compromised Patients, Division One/Special Care Dentistry, Dublin Dental School and Hospital, Lincoln Place, Dublin 2, Ireland; ${ }^{2 *}$ Chairperson of the Specialist Advisory Group in Special Care Dentistry/Senior Lecturer and Consultant in Special Care Dentistry, Department of Sedation and Special Care Dentistry, King's College London Dental Institute, Floor 26, Guy's Tower, London, SE1 9RT ${ }^{*}$ Correspondence to: Dr Janice Fiske

Email: Janice.Fiske@gstt.nhs.uk
}

who look fit can have significant disability and/or complex medical conditions. The clinician relies on his/her ability to establish any such information via a thorough and sensitive medical history and through liaison with the patient's general medical practitioner. This article considers four circumstances where patients have 'hidden' conditions that it is important for the dentist to know about in order to prevent complications as a result of dental treatment. It considers people with epilepsy, latex allergy, acquired or inherited bleeding disorders and those people being treated with oral or intravenous bisphosphonates. Knowing that the patient has a particular condition, its features, how it impacts on oral health, how dental treatment may impact on the condition, and how to modify treatment accordingly means that in many cases these patients can be treated in general dental practice without any cause for concern. Nevertheless, the occasional medical emergency may still occur and ensuring that the dental team knows how to manage such a situation can be life-saving.

\section{EPILEPSY}

Epilepsy is common. Whilst not a condition in its own right, it is a symptom of an underlying neurological disorder. ${ }^{1}$
The lifetime risk of developing epilepsy is $2-5 \%$, with people from socio-economically deprived backgrounds more likely to develop it. ${ }^{2}$

Its aetiology is related to individual susceptibility, known as the 'seizure threshold', and its dynamic interaction with 'seizure precipitants' or 'triggers'. Seventy percent of epilepsy is idiopathic in origin due to genetic factors such as increased neuronal excitability, metabolic disorders of cerebral neurones and decreased inhibition of the motor cortex..$^{1,3-5}$ The remaining 30\% may be secondary to underlying intra-cranial causes, such as space-occupying lesions, trauma, vascular defects, infections and cerebral palsy; and systemic causes, such as hypoxia, hypoglycaemia, metabolic causes, alcohol, opiates and barbiturates. . $^{1,-5}$

The clinical manifestations of seizures vary and reflect the functions of the area of the cortex in which the excessive discharge of neurones arises and to which it spreads. ${ }^{6}$ Epilepsy may be broadly classified into three main groups (see Table 1) based on clinical criteria, seizure characteristics and confirmation by CT and EEG. ${ }^{8}$ Epilepsy can affect the level of consciousness, movement and sensation, and/or result in autonomic or psychic phenomena. ${ }^{5}$ Seizures are usually brief 
and may last from a few seconds to a few minutes. Generally, they have a sudden onset, a spontaneous end point and are frequently followed by a 'post-ictal period' of drowsiness and confusion. ${ }^{1}$ Some seizures are preceded by an 'aura', for example hallucinations, disorientation, slurring of speech, rapid blinking or changes in mood or behaviour. ${ }^{5}$

\section{Management}

The prognosis of epilepsy is influenced by the underlying disease and the severity and frequency of the seizures. Its management is primarily medical and, despite extensive research, often the most appropriate regime for an individual can only be established by trial and error. Drugs are selected primarily on the basis of the type of seizure (see Table 2), starting with a low dose of a single, first-line drug and gradually increasing it until seizure control is achieved. If this is unsuccessful, a second first-line drug is introduced, while the original drug is gradually withdrawn to prevent rebound seizures. ${ }^{7}$ If this is still unsuccessful, then either two first-line drugs are used simultaneously or a second-line drug is tried.

There are an estimated 160,000 people in the UK with epilepsy who require continuing medical treatment. Well managed medication programmes keep about $70 \%$ of people with epilepsy seizure free, however 25,000 of them will have more than one major seizure a month and 60,000 will have more than one minor attack a month. Additionally, there are a further 20,000 patients with severe epilepsy and additional disabilities who may require institutional or community-based care. ${ }^{8}$

\section{Considerations for oral care}

Most people who have seizure disorders attain good seizure control and are capable of receiving routine dental care in general dental practice. ${ }^{3}$ Despite this, some dental professionals may still have concerns about treating people with epilepsy, generally due to uncertainty about when the individual has seizures. ${ }^{3}$ Generally, any such anxieties can be allayed by gathering the right information from the patient. However, an empathic and astute approach needs to be taken to

\section{Table 1 The main types of epileptic seizures and their features}

\begin{tabular}{|c|c|c|}
\hline Type of seizure & Sub-type & Main features \\
\hline \multirow{5}{*}{$\begin{array}{l}\text { Generalised } \\
\text { seizures }\end{array}$} & \multirow{4}{*}{$\begin{array}{l}\text { Tonic-clonic } \\
\text { (or grand-mal) }\end{array}$} & Loss of consciousness \pm brief cry and cyanosis \\
\hline & & Tonic phase - body spasm, head and spine extended \\
\hline & & $\begin{array}{l}\text { Clonic phase - repetitive jerking movements of trunk and } \\
\text { limbs } \pm \text { bruxism/tongue biting/incontinence/salivation. } \\
\text { Seizure lasts } 5 \text { mins, followed by }\end{array}$ \\
\hline & & Clonus - flaccid semi-coma for $10-15$ mins \\
\hline & $\begin{array}{l}\text { Absences } \\
\text { (or petit mal) }\end{array}$ & $\begin{array}{l}\text { Brief periods of unresponsiveness } \\
\text { (episodes last }<30 \text { secs) }\end{array}$ \\
\hline \multirow[t]{2}{*}{ Partial seizures } & Simple & Motor, sensory, autonomic or psychic features \\
\hline & $\begin{array}{l}\text { Complex } \\
\text { (temporal lobe epilepsy) }\end{array}$ & Impaired consciousness, automatic repetitive acts \\
\hline Others & Myoclonic and atonic & \\
\hline
\end{tabular}

\section{Table 2 Drug options by seizure type. Source: reference 26}

\begin{tabular}{|c|c|c|}
\hline Seizure type & First-line drugs & Second-line drugs \\
\hline Generalised tonic-clonic & $\begin{array}{l}\text { Carbamazepine } \\
\text { Lamotrigine } \\
\text { Sodium valproate } \\
\text { Topiramate }\end{array}$ & $\begin{array}{l}\text { Clobazam } \\
\text { Levetiracetam } \\
\text { Oxcarbazepine }\end{array}$ \\
\hline Absence & $\begin{array}{l}\text { Ethosuximide } \\
\text { Lamotrigine } \\
\text { Sodium valproate }\end{array}$ & $\begin{array}{l}\text { Clobazam } \\
\text { Clonazepam } \\
\text { Topiramate }\end{array}$ \\
\hline Myoclonic & $\begin{array}{l}\text { Sodium valproate } \\
\text { (Topiramate) }\end{array}$ & $\begin{array}{l}\text { Clobazam } \\
\text { Clonazepam } \\
\text { Lamotrigine } \\
\text { Levetiracetam } \\
\text { Piracetam } \\
\text { Topiramate }\end{array}$ \\
\hline Tonic & $\begin{array}{l}\text { Lamotrigine } \\
\text { Sodium valproate }\end{array}$ & $\begin{array}{l}\text { Clobazam } \\
\text { Clonazepam } \\
\text { Levetiracetam } \\
\text { Topiramate }\end{array}$ \\
\hline Atonic & $\begin{array}{l}\text { Lamotrigine } \\
\text { Sodium valproate }\end{array}$ & $\begin{array}{l}\text { Clobazam } \\
\text { Clonazepam } \\
\text { Levetiracetam } \\
\text { Topiramate } \\
\end{array}$ \\
\hline $\begin{array}{l}\text { Focal with/without } \\
\text { secondary generalisation }\end{array}$ & $\begin{array}{l}\text { Carbamazepine } \\
\text { Lamotrigine } \\
\text { Oxcarbazepine } \\
\text { Sodium valproate } \\
\text { Topiramate }\end{array}$ & $\begin{array}{l}\text { Clobazam } \\
\text { Gabapentin } \\
\text { Levetiracetam } \\
\text { Phenytoin } \\
\text { Tiagabine }\end{array}$ \\
\hline
\end{tabular}

\section{Table 3 Seizure history information}

Enquire as to:

- The type and aetiology of seizures

- Any known seizure triggers

- Are any triggers associated with dental care, eg stress, light, infections

- Details of any auras experienced

- Does the aura always progress to a seizure

- What to expect when the person has a seizure, eg speed of onset, symptoms, usual length of seizure, speed of recovery

- The date of the last seizure

- The frequency of seizures

- Management of prolonged seizures, eg rectal diazepam, buccal midazolam

- Any episodes of status epilepticus 


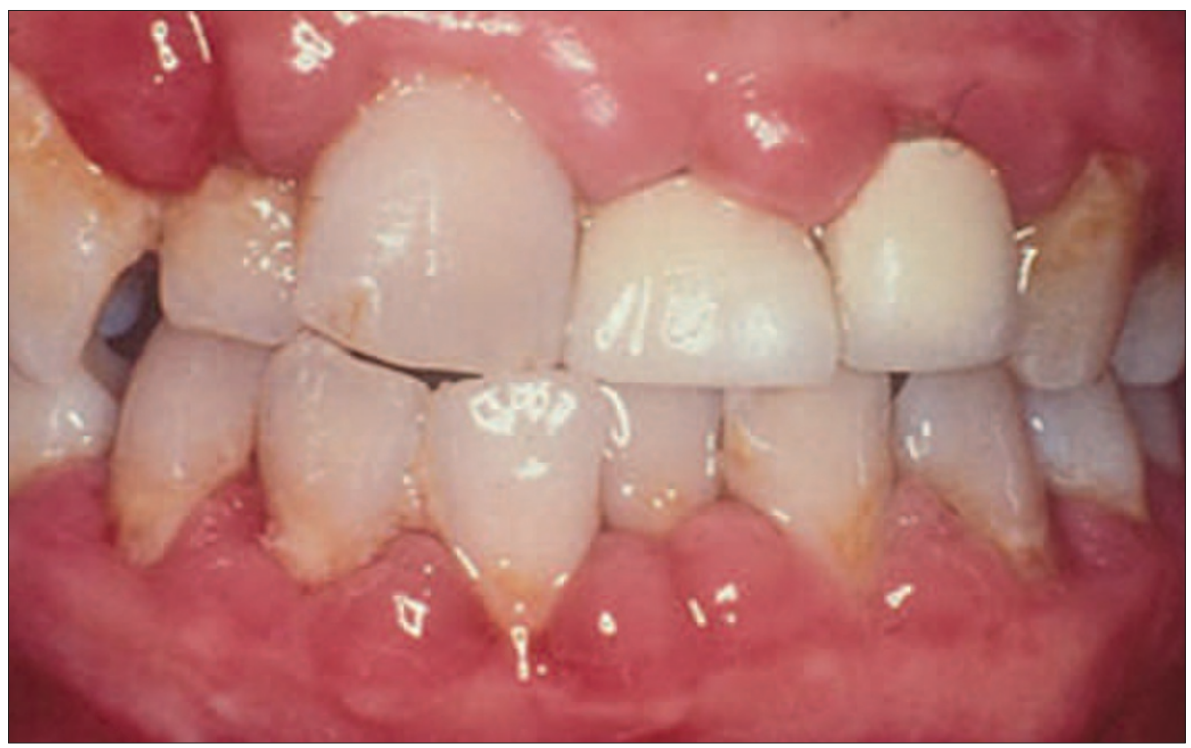

Fig. 1 Gingival hyperplasia associated with phenytoin

history taking as the social stigma still associated with epilepsy can result in some people choosing not to disclose their status. ${ }^{1,3}$

\section{Seizure history}

A thorough medical and seizure history provides information about the seizures and their control that helps the practitioner in the scheduling and planning of appropriate dental treatment. ${ }^{1}$ Table 3 sets out the areas that should be covered in the seizure history. Particularly important are the drug history, which should be checked at each visit; the type, severity and frequency of seizures, to establish if the person is in a good phase or not; and identification of seizure precipitants or triggers so that they can be avoided or minimised during dental treatment. The drug history gives some indication of the degree of seizure control. Frequent medication changes suggest that seizures are not optimally controlled, ${ }^{4}$ and in this situation it may be prudent to delay non-urgent dental care until seizure control is stable or to refer the patient for specialist care. ${ }^{3}$

As a matter of routine, it is advisable to check that the person has taken their routine anti-epilepsy medication, has their emergency medication with them, is well, is not excessively tired and has eaten as usual before embarking on any treatment. ${ }^{1}$ It is prudent to advise the patient to cancel the appointment if they feel that their seizures are poorly controlled on the day of an appointment, as the added stress of dental treatment may trigger a seizure. ${ }^{5}$

\section{Drug therapy}

A number of drugs used in seizure control have implications for oral care or dental treatment. Gingival hyperplasia associated with phenytoin remains the most widely known complication, even though it is no longer a first-line drug (Fig. 1). Reports claim that $50 \%$ of individuals are affected within three to six $^{9}$ months of starting therapy, and adolescents are at particular risk. ${ }^{10}$ Whilst the relationship between gingival overgrowth seems to be related to plasma phenytoin levels, ${ }^{11}$ there is a clear relationship with oral hygiene, ${ }^{1,12,13}$ although there is a genetic link that protects some people, even with very poor oral hygiene, from developing the condition. ${ }^{14}$ Gingival overgrowth is reported to resolve spontaneously in 1-6 months following phenytoin withdrawal. ${ }^{15}$ However, if a person is on long-term phenytoin, gingival overgrowth can make effective oral hygiene difficult and compromises oral health. Treatment options include liaison with the patient's doctor regarding a switch to an alternative anticonvulsant drug and improved oral hygiene. ${ }^{16}$ Surgery can be used to remove the gingival overgrowth but it will recur if phenytoin is still being taken.

Carbamazepine can also cause oral complications including ulceration, xerostomia, glossitis and stomatitis. ${ }^{4}$ Sodium valproate can decrease the

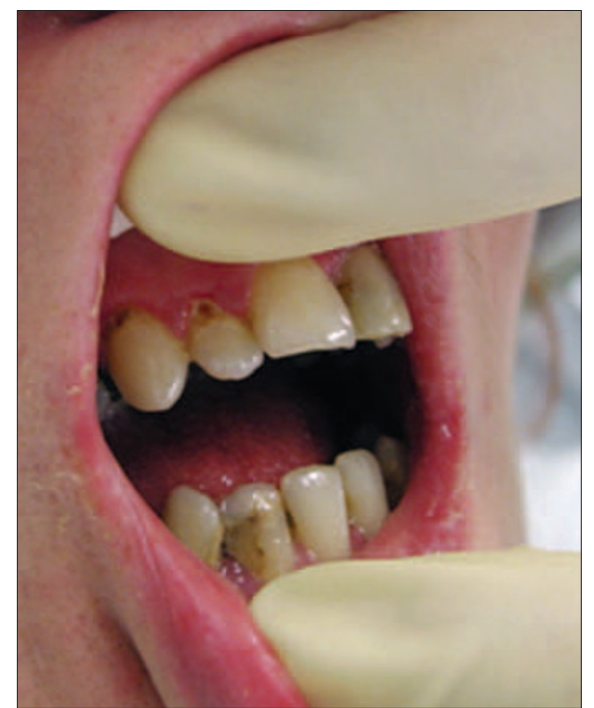

Fig. 2 Caries related to syrup-based medication for epilepsy

platelet count and function, resulting in clotting problems, albeit rarely. ${ }^{4}$ This is insignificant for minor surgery such as straightforward extractions, but a clotting screen is advisable before major surgery. ${ }^{1}$ Any drug prescribed longterm as a syrup-based medicine has the potential to cause dental caries (Fig. 2). Where this is the case, appropriate preventive measures (such as rigorous oral hygiene, use of fluoride and chlorhexidine varnishes, gels or pastes, and regular dental review) need to be enforced..$^{1,17}$ Alternatively, the medical practitioner could be requested to prescribe a sugarfree medicine. ${ }^{17,18}$

A number of medicines used in dentistry can interact with anticonvulsant medication. ${ }^{7}$ For example, aspirin and other NSAIDs can interfere with phenytoin metabolism and can increase the bleeding tendency induced by valproate, ${ }^{5}$ and metronidazole and antifungal agents such as fluconazole and miconazole inhibit the metabolism of phenytoin, increasing its plasma concentration. ${ }^{7}$ Care must be taken if either of these anti-fungal agents have to be prescribed and liaison with the physician to arrange monitoring of phenytoin levels is advised. ${ }^{1}$

\section{Trauma}

Trauma from falls during seizures can cause head injury, subluxation of the temporomandibular joints, dental injury or some other fracture., ${ }^{4,5,19}$ The key predictor for dental injury is seizure 
severity, ${ }^{19}$ and damage can result in subluxation and avulsion of teeth, fractures, and loss of vitality. ${ }^{5}$ Trauma to anterior teeth should be dealt with in the normal way and composite restorations should be the first choice of treatment, as the newer bonding agents and ceramics make large restorations possible. ${ }^{1}$ If a tooth is avulsed and cannot be accounted for, a chest radiograph may be required. ${ }^{5}$ The lips should also be examined for tooth fragments when incisors are fractured.

\section{Fixed and removable prosthodontics}

The presence of a seizure disorder can influence prosthodontic treatment decisions. ${ }^{3}$ As a general rule, it is safer to use fixed prostheses rather than removable appliances, as the latter can dislodge during a seizure causing oral injury or airway obstruction., ${ }^{1,3-5}$ If a denture is unavoidable then a well fitting, retentive cobalt chrome prosthesis with metal backings to anterior denture teeth is the type of choice, as it is less likely than acrylic to fracture (Fig. 3). For full dentures, it has been suggested that either a metal (Fig. 4) or carbon fibrereinforced base (Fig. 5) is used, or that the denture is constructed from high impact acrylic.

A removable prosthesis may be contra-indicated in those individuals with severe or poorly controlled seizures and an alternative option is an implantretained bridge or implant-supported overdenture. Radnai et al. ${ }^{20}$ describe a case report where a 48-year-old with epilepsy was successfully provided with three short span bridges in the lower jaw supported by six dental implants. ${ }^{20}$ As a precaution against damage during seizures at night he was provided with a bite guard.

Large posterior restorations are prone to fracture in someone who clenches during tonic clonic seizures ${ }^{1,3}$ and full crowns have been suggested as preferable in posterior quadrants., ${ }^{1,3}$ Furthermore, full metal crowns should be considered where aesthetically acceptable, as they minimize the chance of fracture which is likely with porcelain., ${ }^{3,5}$ When carrying out treatment, a mouth prop attached to a chain may be used throughout as a precautionary measure,

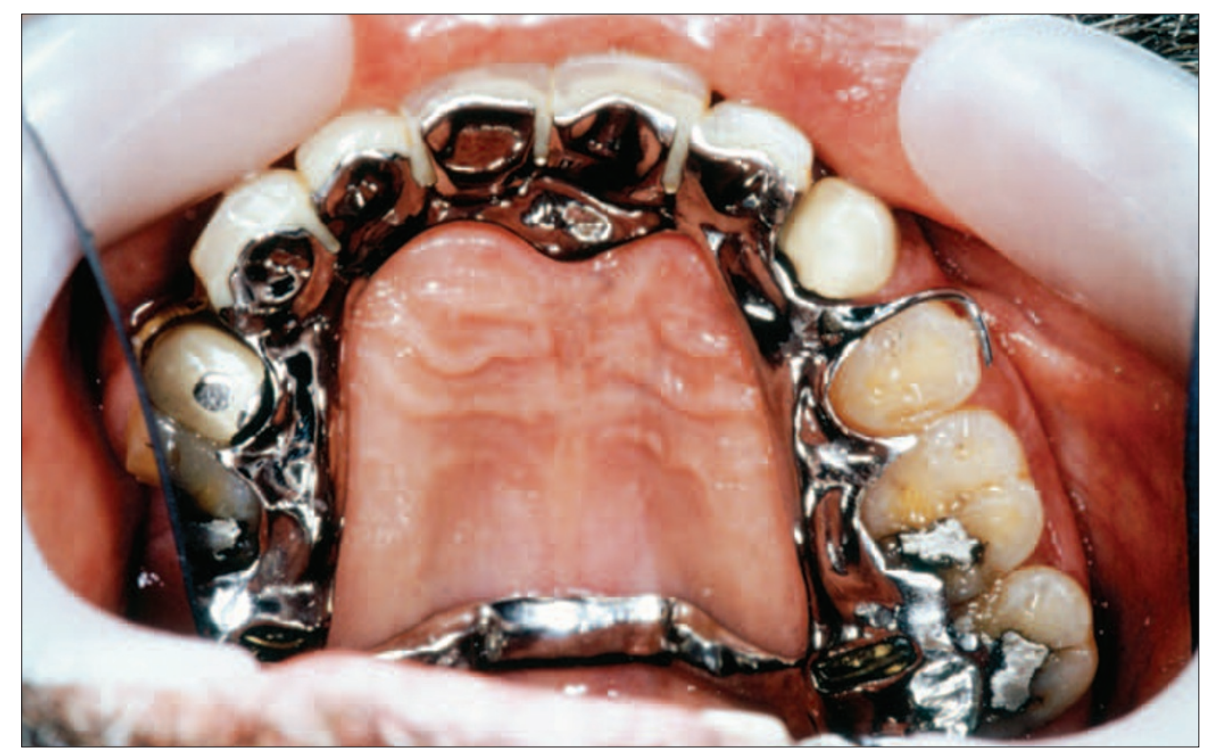

Fig. 3 Well clasped cobalt chromium partial denture with metal backings to incisor teeth to reduce the risk of fracture and inhalation of denture teeth during a seizure (reproduced with kind permission of Dental Update, George Warman Publications)

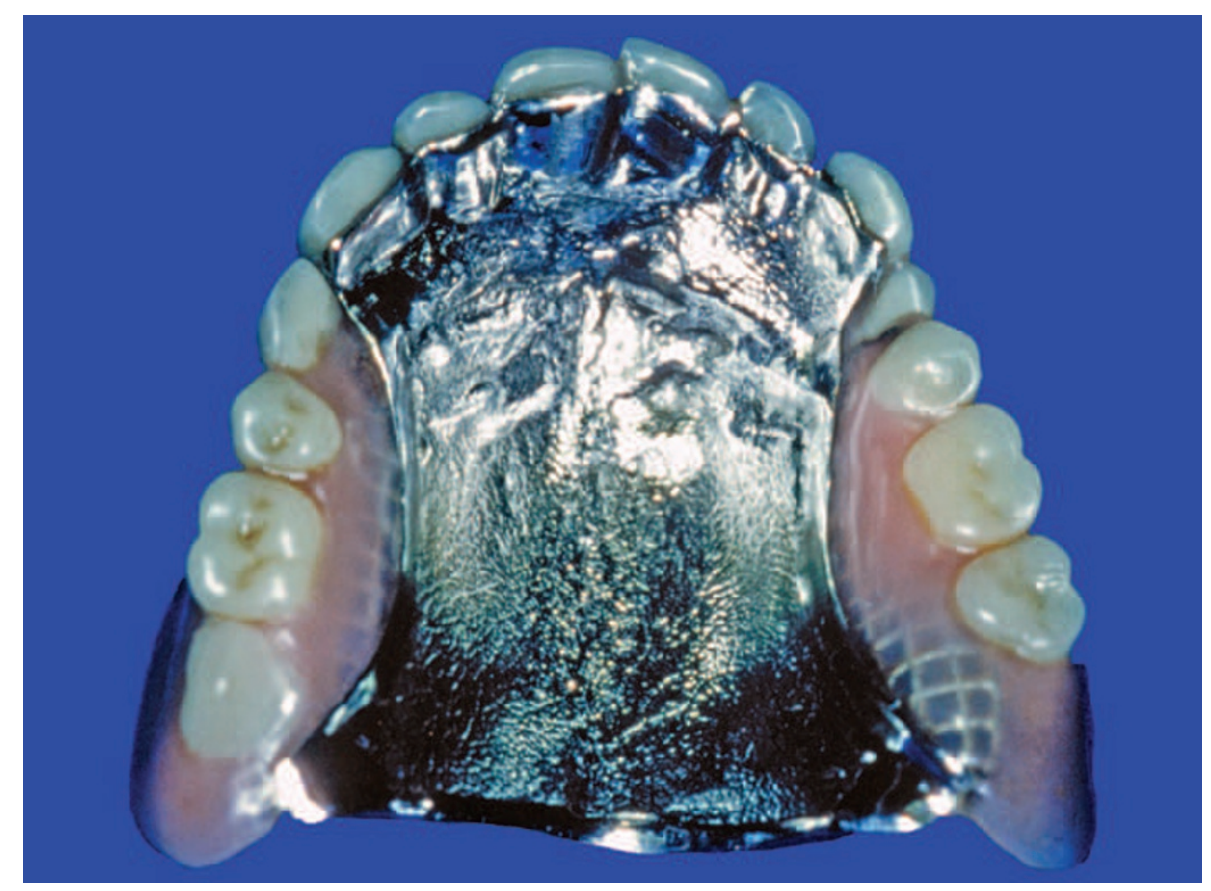

Fig. 4 Complete denture with a cobalt chromium palate and metal extended to support the anterior denture teeth to reduce the risk of fracture during seizure (reproduced with kind permission of Dental Update, George Warman Publications)

and the oral cavity should be kept as free from debris as possible. ${ }^{5}$

\section{Local anaesthesia}

Concern has been raised that local anaesthetic agents containing lidocaine can precipitate seizures in people with epilepsy. This is highly unlikely, as although large doses of lidocaine can cause convulsions when given intravenously, ${ }^{5,21}$ the mechanism of fit caused by lidocaine overdose is quite different from the mechanism of seizures in epilepsy. ${ }^{21}$
It is considered safe to use local anaesthetic agents in people with epilepsy. However, it is prudent, as with any patient, to use an aspirating injection technique and not to exceed the recommended safe dose of anaesthetic agent. ${ }^{21}$

\section{Conscious sedation}

Conscious sedation can be useful to reduce dental anxiety that may act as a seizure trigger. ${ }^{1}$ There are no contraindications to the use of inhalational sedation with nitrous oxide and oxygen, ${ }^{1}$ 


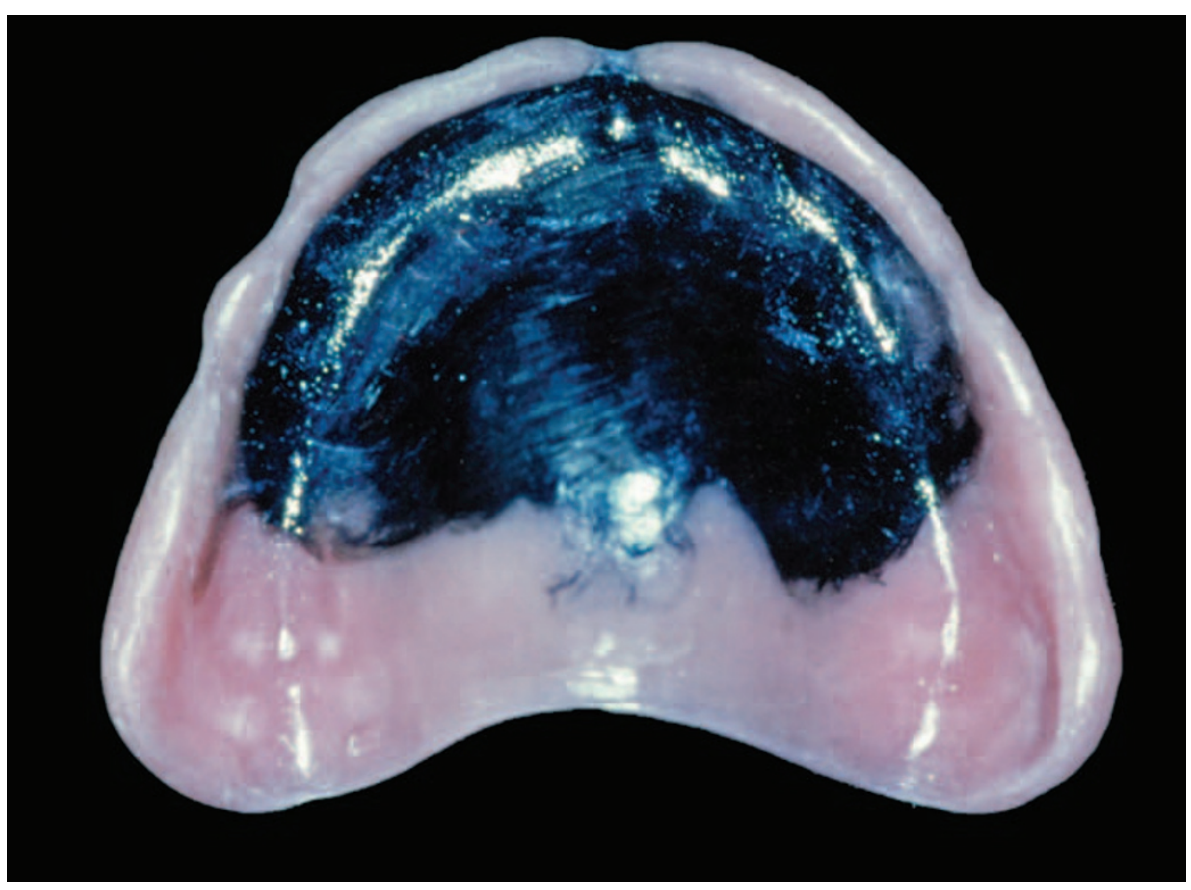

Fig. 5 Complete denture with a carbon fibre reinforced base (reproduced with kind permission of Dental Update, George Warman Publications)

and intravenous sedation with a benzodiazepine can also be useful. ${ }^{1,22}$ However, when sedating patients whose epilepsy is controlled by benzodiazepines (including clobazam and clonazepam), careful titration of the benzodiazepine against the patient response is advocated as the individual may either have a high tolerance to midazolam, or alternatively they could experience an additive effect leading to over-sedation. ${ }^{23}$ In addition, the use of flumazenil, which reverses the effect of the benzodiazepines, should be avoided in this group of patients because of the risk of also reversing the effect of the anti-epileptic drug. ${ }^{1,22,24}$

Intravenous sedation with propofol is relatively contra-indicated, as it has a neuro-excitatory effect and there have been reports of seizure-like phenomena associated with its use. ${ }^{25}$

\section{General anaesthesia}

There are no particular problems associated with general anaesthesia, although it is important to maintain anticonvulsant therapy throughout the peri-operative period. ${ }^{1,5}$ Most anaesthetists are happy for patients to take their usual medication (with a small amount of water if necessary) before anaesthesia. People with poorly controlled seizures or with additional medical problems are better treated on an in-patient basis than as day cases. ${ }^{1,4}$

\section{Management of a seizure in the dental surgery}

Epileptic seizures are the third most common medical incident in dental surgeries $^{16}$ and the dental team should be trained and prepared to manage such an event. When a seizure occurs, the first step is to protect the individual from further injury by stopping treatment, removing all instrumentation from the mouth, moving all equipment out of reach and reclining the dental chair to the supine position as near to the floor as possible. ${ }^{3}$ It is not necessary to move the patient onto the floor and indeed, this is practically impossible when they are fitting, especially in the confined space of a small surgery. ${ }^{1}$ There is no need to restrain the person or place anything in their mouth and furthermore, it is not wise to place fingers into the mouth of a person having a seizure as they may be bitten if the individual clenches during a tonic clonic seizure. The majority of fits are self-limiting and the person will recover quite rapidly.

After a seizure some people sleep deeply. Rather than rousing them, place them in the recovery position and monitor respiration until they wake. They may be disorientated and embarrassed on waking and require reassurance. Once alert, they can go home but must be accompanied.
Table 4 Differential diagnosis for epilepsy

Differential diagnosis for epilepsy includes:

- Syncope

- Hypoglycaemia

- Transient ischaemic attack

- Raised intracranial pressure

- Migraine

- Pseudoseizures

- Panic attacks

- Episodic dyscontrol (rage attacks)

- Sleep disorders, eg narcolepsy

- Day-dreaming

It is important to remember that there are other conditions which should be considered in the differential diagnosis of epilepsy, and these are set out in Table $4 .{ }^{1}$

\section{Management of prolonged or repeated seizures}

If seizures of any type continue unabated for more than five minutes, ${ }^{26}$ or if they stop and start again, then they are considered as a separate entity known as 'status epilepticus' and need to be managed accordingly. ${ }^{27}$ The emergency services should be called immediately and if the patient is having difficulty breathing, or is becoming cyanosed, the airway should be maintained by gently extending the neck if possible. ${ }^{5}$

People with poorly controlled seizures usually carry emergency medication, however this is often diazepam suppositories. Whilst this will stop recurrent seizures in $70 \%$ of patients, it is an unfamiliar route of administration to dental professionals. ${ }^{1}$ Fortunately, midazolam administered by placing it in the buccal sulcus of the oral cavity for absorption through the oral mucosa is becoming more widely used. ${ }^{26}$

Midazolam is a recognised first-line drug for the treatment of status epilepticus, ${ }^{28}$ and as a familiar drug to dentists, is suitable for use in dental practice. ${ }^{5}$ The administration of $10 \mathrm{mg} / 2 \mathrm{ml}$ of midazolam intramuscularly ${ }^{5}$ into the front of the thigh alleviates the problem of finding a vein in a patient who may 


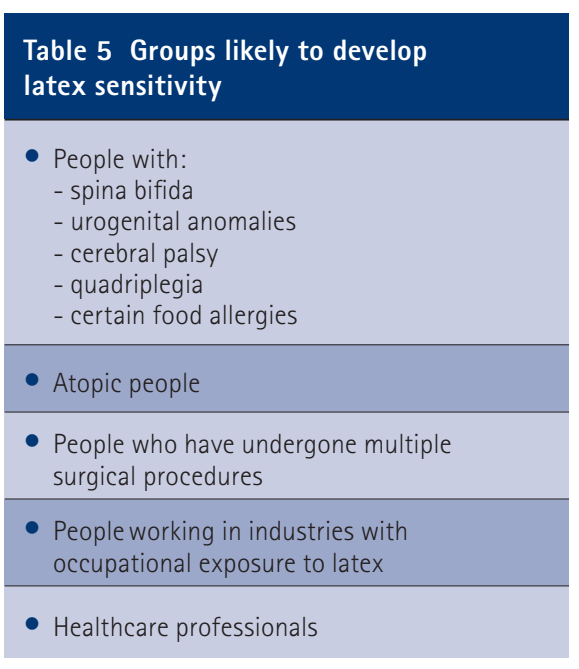

be exhibiting tonic clonic seizures, and is successful in terminating the majority of status epilepticus. ${ }^{1}$ Alternatively, $10-20 \mathrm{mg}$ of diazepam can be given intramuscularly. ${ }^{1}$ It is not necessary to administer oxygen during a fit of short duration. However, if following drug administration the fitting continues or restarts, oxygen should be administered at 10 litres/min and suction used to remove excess saliva from the mouth and pharynx until the emergency services arrive. ${ }^{5}$

All individuals with epilepsy should have a comprehensive care plan that is agreed between them, their family or carers and their primary and secondary care providers, including the dental team. ${ }^{26}$ Epilepsy is common and with a carefully taken medical and seizure history, and proper training in managing seizures, the primary care dental team should feel confident, and be prepared, to treat most people with the condition.

\section{LATEX ALLERGY}

Latex allergy occurs in 1-5\% of the general population ${ }^{29}$ and is more common in children and young working adults because of the increased medical and/ or occupational exposure to latex over the past two decades. Dental practitioners need to be aware of individuals who may have an increased risk of being latex sensitive, ${ }^{30}$ including themselves and their staff, and eliminate, substitute or control the use of natural rubber latex (NRL) in daily practice as far as possible. ${ }^{31}$ Clark $^{32}$ reported that general dental practitioners indicated they were prepared to accept patients with latex

\section{Table 6 Pre treatment assessment to identify latex allergy}

- Do you have a history of allergies to drugs, foods, fruits, peanuts, adhesive tape or latex?

- Have you ever experienced a severe allergic reaction?

- Do you have hives or develop itching after contact with things such as balloons, household gloves, elastic bands or condoms?

- Have your lips or tongue ever been swollen following dental treatment?

- Has your face ever been swollen or red following a local anaesthetic?

- Have you ever developed asthma, breathing problems, itching eyes or a runny nose associated with work?

sensitivities but wanted more information about the latex content of equipment to be fully aware of the necessary precautions required. Subsequently, good practice guidelines for managing patients with latex allergy were published by the FGDP (UK). ${ }^{33}$

Whilst dentists routinely ask patients about allergies there is merit in including screening questions to identify those individuals who have increased potential for sensitivity so that routine practice can be modified accordingly. ${ }^{34}$ Table 5 sets out the groups identified as most likely to develop latex sensitivity. ${ }^{29,35}$ They include up to $10 \%$ of rubber industry workers and up to $14 \%$ of paramedics and emergency department staff. ${ }^{29}$ However, by far the highest prevalence of latex allergy is in people with spina bifida, with reports as high as $28-67 \% .{ }^{36}$ This group may also have a genetic predisposition to latex sensitisation and with continued exposure to a higher incidence of latex products throughout their lives, have a 1 in 2-4 risk of developing latex sensitivity. People with congenital urogenital abnormalities are also at high risk of sensitisation because of early repeated contact with rubber bladder catheters and clinical gloves. ${ }^{37}$ Interestingly, the prevalence of latex allergy is also increased in persons with allergies to tropical fruits and cross reacting antigens have been found between latex and avocado, kiwi, papaya, peach, nectarines, bananas, chestnuts and figs. ${ }^{29,31}$

All of these patient groups should have a detailed pre-treatment assessment to identify possibility of latex allergy. Table 6 gives examples of the sort of questions that should be asked. ${ }^{34}$ The responses to these questions can be used to categorise the patient's risk and management strategies can be modified accordingly. Diagnosis of latex allergy is via clinical history, medical history, serology and dermatological skin prick tests. Liaison with the patient's dermatologist or allergist can establish the presence and severity of a confirmed or suspected latex allergy. Field ${ }^{34}$ describes three groups of latex allergy risk:

Group one - people with a known history of anaphylaxis to latex. They should only be treated in a dedicated environment which is completely latex screened and where there are prepared staff trained and competent to deal with severe allergic reactions with non-NRL emergency and resuscitation equipment. If the individual carries an adrenaline auto-injector, such as an epi-pen, it should be easily available at all times throughout dental treatment.

Group two - people who have a history of localised type IV reactions to NRL or who have exhibited signs and symptoms such as rhinitis, urticaria or conjunctivitis. Preferably, they should receive treatment in a latex-free environment. However, in liaison with their allergist/ dermatologist it may be possible for them to be treated in a latex-modified environment, for example using latex- and powder-free gloves, latex-free dam, teflon amalgam carriers, prophylaxis brushes rather than rubber cups, and local anaesthetic agents in plastic cartridges. Also, appointments should be given early in the day when there are less circulating allergens in the environment.

Group three - people who have not exhibited symptoms of latex allergy but fall into one of the latex sensitive 'at risk' groups. The dental team should be alert to, and recognise any adverse signs of sensitivity. 
The signs and symptoms of an allergic reaction to NRL are the same as those due to other allergens encountered in the dental practice. ${ }^{31}$ It may present as nonimmunological inflammation similar to eczema (a type IV delayed response contact dermatitis) or a full-blown type I NRL allergy, with severity ranging from localised urticaria (hives) and wheezing to a life threatening anaphylaxis and associated angioedema. The onset of reaction is usually seen between 5 and 60 minutes after exposure. Acute anaphylaxis is a medical emergency and an ambulance should be summoned immediately and the paramedic team advised of the latex allergy. ${ }^{34}$ Interim management by the dental team will be in accordance with local protocols. Adrenaline is the key drug and can be delivered intramuscularly in a dose of $0.5-1 \mathrm{mg}$ of $1: 1,000$ concentration. ${ }^{7}$ For obvious reasons it is good practice to ensure that the drug box and contents are latex-free.

Full guidelines for dealing with emergency treatment of anaphylactic reactions, and frequently asked questions, can be found on the Resusitation Council UK's website. ${ }^{38,39}$

\section{BISPHOSPHONATES}

Bisphosphonates are a class of drugs used increasingly to treat osteoporosis, multiple myeloma, Paget's disease, osteogenesis imperfecta and malignant bone metastases. The efficacy of these agents in treating and preventing the significant skeletal complications associated with these conditions has had a major positive impact for patients and is responsible for their widespread use in medicine. ${ }^{40}$ However, despite these benefits, an increasing body of literature suggests that bisphosphonate use, especially of intravenous (IV) preparations, is associated with osteonecrosis of the jaws. ${ }^{41}$ This results from a complex interplay of reduced osteoclast activity, altered bone metabolism, local trauma, increased demand for bone repair and hypovascularity. ${ }^{42}$

To distinguish bisphosphonate-related osteonecrosis of the jaws (BRONJ) from other delayed healing conditions, it has been agreed that patients must have current or previous treatment with a bisphosphonate; exposed, necrotic bone in the

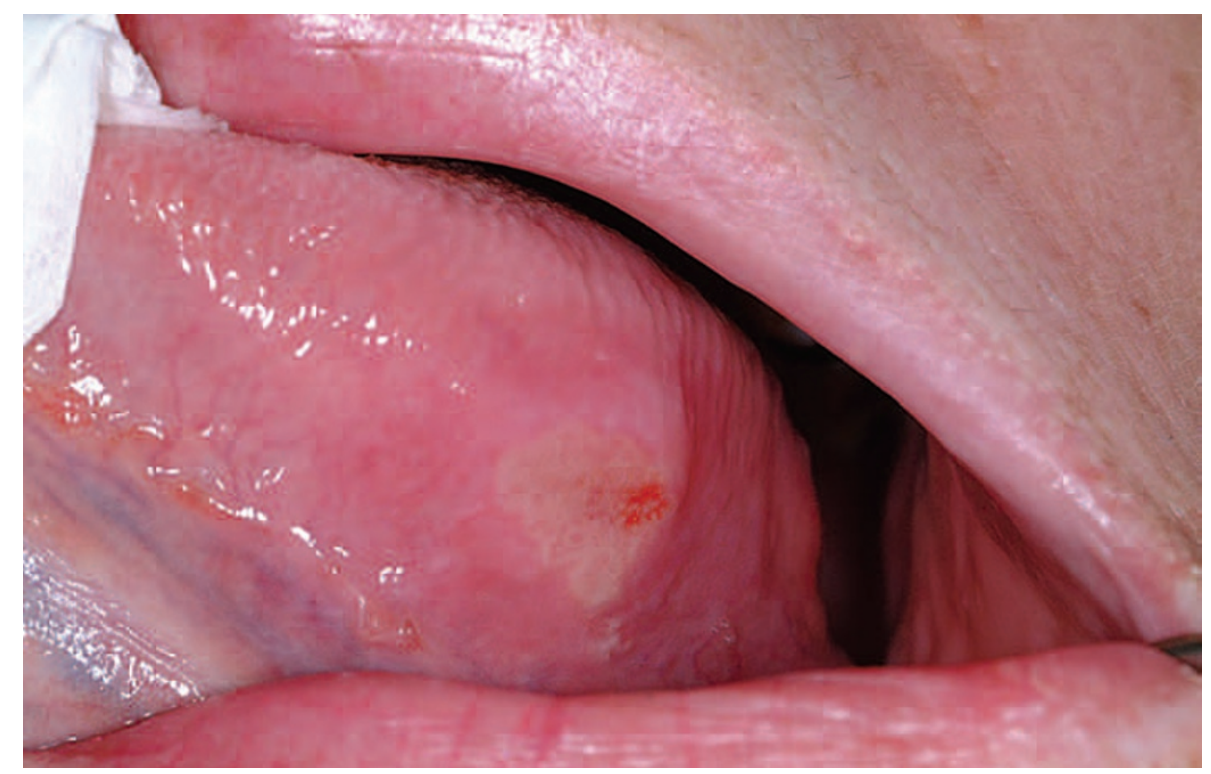

Fig. 6 Ulcerated tongue which was the presenting symptom of the bisphosphonate-related osteonecrosis of the jaw seen in Figure 7

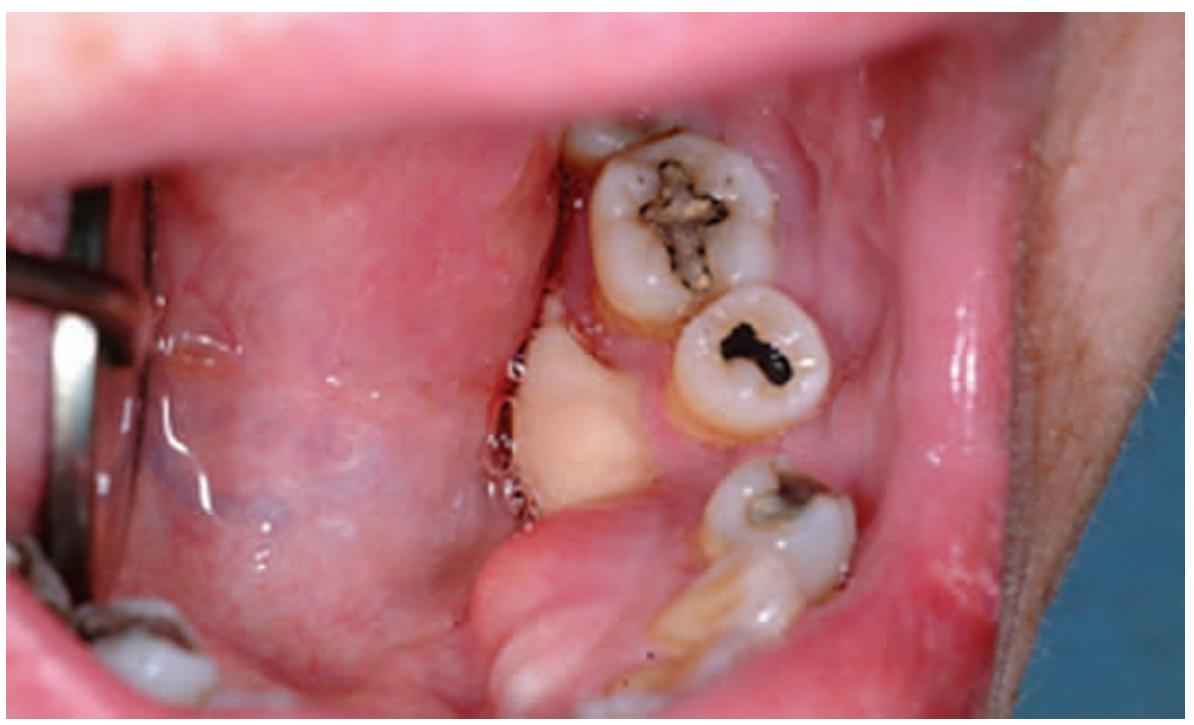

Fig. 7 Bisphosphonate-related osteonecrosis of the jaw related to a mandibular torus

maxillofacial region that has persisted for more than eight weeks; and no history of radiation therapy to the jaws. The most common presentation is absent or delayed hard or soft tissue healing after dental extractions or surgery. ${ }^{42}$ However, BRONJ may present clinically as spontaneous areas of exposed yellow-white hard bone with smooth or ragged borders. ${ }^{41}$ Patients are usually asymptomatic but may develop severe pain because of secondary infection. ${ }^{41,42}$ In patients who seemingly develop BRONJ spontaneously, there is usually a history of trauma to the oral soft tissues surrounding the area of necrotic bone (Figs 6 and 7). ${ }^{42}$

Bisphosphonates are marketed under the brand names Actonel, Actonel+Ca, Aredia, Boniva, Didronel, Fosamax,
Fosamax+D, Reclast, Skelid and Zometa. They are delivered orally or intravenously. Bisphosphonates in tablet form are commonly used to prevent and treat osteoporosis in post-menopausal women. The World Health Organization launched a fracture risk assessment tool which could have a huge impact in reducing the number of people who break bones unnecessarily because of osteoporosis. ${ }^{43}$ However, this will no doubt lead to the likelihood of more patient groups being offered preventive treatment for osteoporosis from their primary care practitioner, including the use of licensed and effective oral bisphosphonate therapy. ${ }^{44}$

Bisphosphonates are used intravenously in the management of hypercalcaemia of malignancy, skeletal events 
related to bone metastases from tumours, and lytic lesions of multiple myeloma. ${ }^{45}$ When used in cancer chemotherapy, the drugs are delivered intravenously in high doses and the recipients have the highest potential for developing BRONJ, representing $94 \%$ of published cases. ${ }^{41}$ Zoledronate (Zometa) and pamidronate (Aredia) exert several anti-tumour effects and exhibit particularly high potency. ${ }^{42}$ Their significant effect on the quality of life for patients with advanced cancer, where disease would otherwise cause bone pain and possibly even spontaneous fractures, ${ }^{46}$ means that their benefit is considered to outweigh the risk associated with their use. ${ }^{40-42,46,47}$

Table 7 sets out the groups of people who can be treated preventively with bisphosphonates. Some groups who could be treated with oral forms are prescribed the drug intravenously as compliance with the use of either weekly or daily oral bisphosphonates is poor. ${ }^{48}$ This is in part due to them needing to be taken on an empty stomach with the tablets swallowed whole and the person remaining sitting or standing for at least 30 minutes after taking them. ${ }^{48}$ People unable to comply with these restrictions, who have dyspepsia, dysphagia, gastrointestinal malabsorption, or who have reported side-effects such as inflammation and ulceration of the oesophagus, stomach pains, nausea and inflammation of the tongue, are usually considered for intravenous preparations. ${ }^{44}$

General dental practitioners have a key role to play in identifying patients at risk of developing BRONJ, educating and advising them, reducing oral risk factors and initiating early specialist referral where BRONJ is suspected. ${ }^{49} \mathrm{~A}$ thorough medical and drug history will highlight potential risk factors enabling dental practitioners to implement suitable preventive measures and management strategies.

Guidance based on expert opinion has been widely published. ${ }^{41,42,45,46}$ Most recommended treatment modalities for patients unavoidably undergoing extractions or surgical work are based on expert and consensus opinion and reviews of trends in case studies. Effectiveness of bisphosphonate 'drug holidays' prior to surgical intervention, suitable pre- and

\section{Table 7 People who may benefit from treatment with bisphosphonates}

- Women with early menopause or hysterectomy

- Men with low testosterone levels

- People on long-term steroids, eg for SLE, rheumatoid arthritis, asthma, COPD

- People with metabolic disorders, eg hyperthyroidism, hyperparathyroidism

- People with medical conditions causing long-term immobility or nutritional deficiency, eg Crohn's disease, coeliac disease, ulcerative colitis

- People with medical conditions associated with secondary osteoporosis, eg primary biliary cirrhosis, renal disease, eating disorders, alcohol abuse

\section{Table 8 Systemic diseases causing coagulopathies. Source: reference 54}

\begin{tabular}{l|l|l} 
Disease & Common causes & Resulting coagulation defect \\
\hline $\begin{array}{l}\text { Renal failure } \\
\text { and uraemia }\end{array}$ & $\begin{array}{l}\text { Diabetes mellitus } \\
\text { Glomerulonephritis } \\
\text { Pyelonephritis } \\
\text { Hypertension }\end{array}$ & $\begin{array}{l}\text { Inhibition of adhesion and primary aggregation } \\
\text { of platelets from glycoprotein Ilb-IIla deficit }\end{array}$ \\
\hline Hepatic failure & $\begin{array}{l}\text { Alcohol abuse } \\
\text { Hepatitis B and C } \\
\text { Hepatocellular carcinoma }\end{array}$ & $\begin{array}{l}\text { Loss of liver tissue and all clotting factors } \\
\text { except VIII and von Willebrand's factor }\end{array}$ \\
\hline $\begin{array}{l}\text { Bone marrow } \\
\text { failure }\end{array}$ & $\begin{array}{l}\text { Alcohol abuse } \\
\text { Cancer (eg leukaemia) } \\
\text { Myelosuppressive medications } \\
\text { (eg chemotherapy for cancer) }\end{array}$ & $\begin{array}{l}\text { Reduced number of functioning platelets } \\
\text { Anaemia from bone marrow suppression }\end{array}$ \\
\hline
\end{tabular}

post-operative antimicrobial regimes, and use of oral disinfectants to prevent infection and aid healing are all awaiting evidence from longitudinal studies and clinical trials and remain inconclusive at present. ${ }^{40,41,45-47,49}$ The authors recommend that current guidelines and recommendations should be consulted and followed as they evolve.

The most recent position paper groups the risk factors for the development of BRONJ in three categories: ${ }^{45}$

1. Drug-related - potency, choice of bisphosphonate, route of administration, duration of therapy

2. Local - dento-alveolar surgery, anatomy, concomitant inflammatory oral disease (periodontal and dental infection)

3. Demographic/systemic - age, race, medical co-factors and cancer diagnosis.

What is clear is that prevention of BRONJ is currently the best approach to managing it. ${ }^{46}$ To date, most cases have developed in patients receiving intravenous preparations for the treatment of multiple myeloma or metastatic cancer. ${ }^{41}$ Ideally, these patients should have a thorough oral examination, with any unsalvageable teeth removed and all invasive procedures completed so that optimal oral health is achieved and maintained before bisphosphonate treatment commences. ${ }^{45}$ If this is not possible, the goal should be to achieve this status within six months of commencement of intravenous bisphosphonate therapy, as anecdotal evidence points to a low incidence of osteonecrosis occurring in this period. ${ }^{46}$

It is critical that patients are appraised of the importance of both oral hygiene and regular dental check-ups. Wherever possible, dento-alveolar surgery including extractions, implant placement, periapical surgery and periodontal surgery should be avoided in patients taking intravenous bisphosphonates, as they are at least seven times more likely to develop BRONJ than patients who are not having surgery. ${ }^{42,45,46}$ For non-restorable teeth, decoronation and endodontic treatment of the remaining root(s) is advocated..$^{50}$ However, it is of note that the presence of infection and periodontal disease 
have been shown to initiate spontaneous BRONJ, ${ }^{41,42,46}$ so each case should be risk assessed on its own merits and the individual informed of the relative risks of providing, or not providing, treatment.

Patients with dentures should be examined for any potential areas of mucosal trauma, especially in the lingual flange area. Spontaneous necrosis associated with both tori and trauma from dentures has been reported in individuals taking oral bisphosphonates. ${ }^{41,45,51}$ Therefore, dentures should be reviewed regularly and patients with anatomical features such as tori or pronounced mylohyoid ridges should be monitored vigilantly and specifically instructed to report any pain, swelling or exposed bone. ${ }^{41,45}$

Because bisphosphonates are incorporated into the skeleton without being degraded, they are remarkably persistent drugs and their estimated half life is at least 10 years. $^{52}$ The risk of associated complications seems to increase with the increased time of bisphosphonate use for both oral and IV preparations. The risk of developing BRONJ with oral bisphosphonates, while small, appears to increase when their duration of use exceeds three years, and the risk increases in the presence of certain co-morbidities such as chronic corticosteroid use, diabetes or the use of chemotherapeutic agents. ${ }^{45}$ Currently the degree of risk for osteonecrosis in patients taking oral bisphosphonates is uncertain and warrants careful monitoring. ${ }^{41}$ Preventive oral care, including regular radiographic and periodontal review, should be undertaken. This must include patient awareness training of the risks and appearance of BRONJ, and encouragement to report any exposed bone or soft tissue ulceration early on.

Kearns $^{51}$ suggests that practitioners should consider amending current medical history-taking practice to focus on areas more recently associated with increased use of bisphosphonate therapy. He warns that patients sometimes do not report medication which is delivered intravenously by a physician unless asked specific or direct questions, and that many patients may fail to include a weekly tablet taken for osteoporosis within a list of multiple medications taken daily. ${ }^{51}$ In addition, those patients who have previously received treatment or surgery for solid tumours such as lung cancer, breast cancer and prostate cancer may euphorically omit reporting their ongoing monthly intravenous bisphosphonate injection from their specialist team once their chemotherapy has subsided and they are in remission. ${ }^{51}$

Bisphosphonate use remains an important area of vigilance for primary care practitioners in view of the increasing use of these drugs for groups of patients who are likely to be seen in general practice. The National Institutes of Health announced funding opportunities for research into BRONJ in 2006. Thus, it is likely that evidence-based information that will allow clinicians to make more accurate judgements about risk, treatment selection and outcomes relevant to patient needs will start to become available. ${ }^{42,45}$

\section{BLEEDING DISORDERS}

A bleeding disorder arises if there is a problem in any part of the haemostatic and clotting pathway and can be acquired or congenital..$^{53}$ A carefully taken medical history helps establish the likelihood of excessive or prolonged bleeding. Indicators of a bleeding condition include diagnosis or family history of a bleeding disorder, treatment with anticoagulant medication and liver disease, as well as factors such as abnormal bruising, prolonged bleeding from cuts, nose bleeds, menorrhagia, and previous haemorrhage after dental extractions, childbirth or surgery. ${ }^{53}$ Ninety percent of post-operative bleeding is the result of local causes and can be stopped using simple measures and should not recur. However, when a bleeding disorder is suspected, referral for investigation prior to undertaking invasive dental treatment likely to cause bleeding is essential. ${ }^{53}$

\section{Acquired bleeding conditions}

Acquired bleeding conditions occur as a result of liver disease and platelet disorders (Table 8$)^{54}$ or as the result of anticoagulant therapy. People who have liver failure and/or alcoholism, renal failure, thrombocytopaenia, and/or are receiving a current course of cytotoxic or chemotherapy will have coagulation and clotting disorders and should not receive surgery in primary care without liaising with the physician responsible for their condition. ${ }^{55}$

\section{Anticoagulant therapy}

A significant proportion of people are on prescribed anticoagulants to provide prophylactic treatment for ischaemic heart disease, myocardial infarction and deep vein thrombosis. This number is growing and the dental team will increasingly have patients who are taking anticoagulant drugs that target either platelets or the clotting pathway.

\section{i) Antiplatelet therapy}

Commonly used drugs include aspirin and dypiridamol. Many people take 75 $\mathrm{mg}$ aspirin daily as a prophylactic measure, and this regime does not pose a significant bleeding risk for dental procedures. However, when used in combination, antiplatelet medications have a synergistic effect and impair platelet function for the platelet's lifetime (halflife of 8-12 days). ${ }^{57}$ Current advice from the UK Medicines Information Service regarding dental treatment is that antiplatelet medications (including aspirin in combination with clopidogrel) do not have to be stopped or altered before primary care dental surgical procedures and locally applied measures are usually adequate to achieve coagulation. ${ }^{55}$

\section{ii) Coumarin therapy}

Warfarin (a vitamin K antagonist) is the most commonly prescribed coumarin. It is used as prophylaxis or treatment for deep vein thrombosis, patients with prosthetic heart valves, and for people with atrial fibrillation. It prolongs both the prothrombin time and the activated partial thromboplastin time and its effects are monitored using the International Normalised Ratio (INR). The usual INR therapeutic range for deep vein thrombosis is $2-3$, and up to 4.5 for patients with prosthetic heart valves.

It is considered that people with an INR of 4 or less can safely undergo dental surgery in general dental practice without any dose adjustment to their warfarin. ${ }^{56}$ Current advice is that warfarin is not stopped before dental surgical procedures as the rebound risk of thromboembolism following withdrawal outweighs the risk 
of oral bleeding. ${ }^{56}$ The risks are $1 \%$ and $0.2 \%$, respectively. ${ }^{57}$ The patient might bleed more than normal but the bleeding is easily controlled with local measures (Table 9). Warfarin regimes should only be stopped or changed under supervision of the anticoagulant clinic and the patient must be discouraged from unilaterally reducing or withdrawing it prior to dental treatment.

Ideally the INR should be checked within the 24 hour period prior to treatment, ideally on the day of the procedure. This can be done in the dental surgery using a self-testing machine such as the Coagucheck Monitor. However this is not always possible in the primary care setting, and for patients with a stable INR, measurement within 72 hours before the procedure is acceptable. ${ }^{56}$ Patients normally carry a record card of their INR readings, from which the stability of control and average INR can be obtained. Irregular readings suggest the INR is poorly controlled. People with a poorly controlled INR, or an INR $>4$ who require multiple or difficult extractions should be seen in hospital. ${ }^{56}$ It is considered safe to scale a patient on anticoagulants provided the INR is $<4$, although it is prudent to scale around one or two teeth and observe how long haemostasis takes before proceeding further. There is a theoretical risk of bleeding into fascial planes following an inferior dental block and where possible this procedure should be avoided. If its use is unavoidable, an aspirating technique should be used and the injection given slowly to minimise tissue damage. ${ }^{56}$ Tranexamic acid mouthwash can be useful for arresting gingival haemorrhage, although its routine use is not necessary for this patient group.

Warfarin interaction with other drugs generally leads to an elevated INR and risk of spontaneous bleeding. All antibiotics affect the INR value to some extent, although single dose amoxicillin has little effect. Metronidazole potentiates the effect of warfarin and should be avoided if possible. If it is necessary to prescribe antibiotics it is important to consult the haematologist/anticoagulation clinic so that the INR value can be monitored during antibiotic therapy. Antifungal agents (such as fluconazole,

\section{Table 9 Local measures to achieve haemostasis}

To reduce the risk of post-operative bleeding:

- Carry out all procedures with minimal trauma

- Particlarly, carry out any surgical procedures with minimal trauma

- Use a local anaesthetic agent with a vasoconstrictor

- Use haemaostatic agents in sockets, eg oxidised cellulose such as Surgicel, or collagen sponges

- Suture sockets with just enough tension to stabilise gum flaps and avoid clot disturbance

- Use of resorbable sutures removes the risk of any trauma associated with suture removal

- Appropriate post-operative instructions with emphasis on avoiding clot-disturbing procedures and what to do in the event of post-operative bleeding

Additionally, for patients anticoagulated on warfarin:

- Check INR stability and that the level is $<4$

- Use of tranexamic acid mouthwash, if available, $4 \times$ a day for 2 days

- Avoid prescribing NSAIDs

Table 10 Inherited coagulation disorders

\begin{tabular}{l|l|l|l}
\hline Type & Factor deficiency & Hereditary pattern & Prevalence \\
\hline Haemophilia A & Factor VIII & $\begin{array}{l}\text { X-linked recessive trait } \\
30 \% \text { have no family history }\end{array}$ & $\begin{array}{l}1 \text { in 10,000 males } \\
\text { Female carriers } \\
\text { can have a mild } \\
\text { bleeding tendency }\end{array}$ \\
\hline $\begin{array}{l}\text { Haemophilia B (or } \\
\text { Christmas disease) }\end{array}$ & Factor IX & X-linked recessive trait & 1 in 25-30,000 males \\
\hline $\begin{array}{l}\text { von Willebrand's } \\
\text { disease }\end{array}$ & $\begin{array}{l}\text { von Willebrand's factor } \\
\text { leading to low factor } \\
\text { VIII activity and reduced } \\
\text { platelet adhesion }\end{array}$ & $\begin{array}{l}\text { Dominant inheritance } \\
\text { pattern }\end{array}$ & $\begin{array}{l}1 \text { in 100 males } \\
\text { and females }\end{array}$ \\
\hline
\end{tabular}

Table 11 World Hemophilia Federation guidelines for dental treatment

- Focus on prevention of dental disease

- Regular reviews tailored to the individual's need

- Initial liaison with the person's haemophilia centre to confirm disease severity and management

- Post-operative management with tranexamic acid and local measures

- Judicious planning of procedures likely to cause bleeding to minimise the episodes requiring anticoagulant therapy

miconazole and ketoconazole) potentiate the effect of warfarin several fold, even after topical use, and must be avoided. It is prudent to refer to the latest Dental practitioners' formulary for possible drug interactions before prescribing for patients taking warfarin.

\section{Hereditary or congenital bleeding disorders}

Congenital bleeding disorders (CBD) have the potential to cause mild or severe bleeding tendencies. ${ }^{58}$ The most common types of CBD, their hereditary pattern and prevalence are set out in Table 10. Many protocols and guidelines for managing the risk of bleeding following dental treatment have been published and, though few are evidencebased, ${ }^{59-61}$ they mostly recommend the use of clotting factor replacement therapy before invasive dental treatment. The use of careful techniques, local measures (Table 9) and appropriate use of antifibrinolytic agents post-operatively has resulted in a reduced need for coagulation factor replacement prior to invasive dental treatment, including some 
minor oral surgery procedures. ${ }^{59}$ Despite this, people with CBD face barriers to accessing dental care, for example needing to travel long distances to specialist dental centres, long waits for access to services, increased treatment needs due to neglect and fear, and the costs, both financial and emotional, associated with these. ${ }^{62}$

The majority of patients with CBD can be safely treated in mainstream general dental services or via shared care with a specialist centre where more invasive or surgical procedures are required ${ }^{63}$ Their successful management is the result of co-operation between haematologists and dentists. Gomez-Moreno et al. ${ }^{58}$ conducted an extensive review of the current literature and concluded that the management of people with CBD cannot be based on a single rigid protocol and that each haematological disorder and individual patient requires an individualised approach. They recommended that the dental professional must consider the type of hereditary haematological disorder involved, whether standard dental treatment should be modified, whether factor replacement therapy or drugs are required to carry out dental treatment without risk of haemorrhage, and whether any prescribed drugs are contra-indicated. ${ }^{58}$

\section{Haemophilia A}

The severity of haemophilia A is dependent on the plasma levels of active factor VIII. ${ }^{5}$ It is diagnosed via clinical history and diagnostic laboratory findings, which are characterised by a normal bleeding time and INR (prothrombin time) but a prolonged activated partial thromboplastin time (APTT) and low levels of factor VIII. Disease is considered severe when the plasma level of factor VIII is $<1 \%$ of normal, moderate if between 2-5\% and mild if it is between 6-40\%. ${ }^{62}$ Haemophilia A typically manifests in childhood as easy bruising and prolonged bleeding from wounds following injuries. Most people with mild or moderate disease lead relatively normal lives but severe haemophilia results in haemarthrosis, from spontaneous bleeding into muscles or joints. Recurrent haemarthrosis can result in deformity and, in extreme cases, joint replace- ment. ${ }^{53}$ Bleeding into the cranium after only a mild injury can lead to death. ${ }^{53}$ Moderate haemophilia is usually only problematic after trauma or surgery, and mild haemophilia may go undiagnosed until an event such as prolonged bleeding following a dental extraction. ${ }^{5}$

The treatment of people with either haemophilia A or B involves the replacement of the deficient clotting factors (porcine or recombinant) by intravenous infusion to control or prevent bleeding. In severe cases this necessitates daily injections which most people selfadminister, improving both quality of life and convenience. ${ }^{5}$ The use of factor concentrate is not without its drawbacks, and between $15-25 \%$ of people develop inhibitors or antibodies with repeated use, making their condition more difficult to control. ${ }^{53}$

\section{von Willebrand's disase (vWD)}

In this CBD there is an extended bleeding time due to poor platelet function and low levels of both circulating von Willebrand factor (vWF) and ristocetin co-factor (which promotes collagen binding), as well as low factor VIII activity. ${ }^{65}$ vWD is usually characterised by features similar to platelet dysfunction, such as menorrhagia, gastro-intestinal bleeding and purpura of mucous membranes and skin. Gingival bleeding is more common than in haemophilia.

Seventy-five percent of people have mild or Type $1 \mathrm{vWD}$, which is usually treated using the synthetic hormone desmopressin (DDAVP). This stimulates release of the available vWF from the endothelial cells, producing a temporary rise in both vWF and factor VIII. Desmopressin is usually given by intravenous infusion over 20 minutes by haemophilia centre staff or a self-administered highstrength nasal spray. Tranexamic acid (TA), an anti-fibrinolytic agent used to help stabilise blood clots in minor bleeds, is also useful. It is usually administered in tablet form, but can be given in syrup form or intravenously, ${ }^{65}$ and in the dental situation it can be used as a mouthwash. ${ }^{66}$ Some of the more severe types of vWD require factor replacement therapy. Currently, this is derived from human plasma as no recombinant vWF concentrate is yet available.

\section{Blood-borne viruses}

Patients with CBD were exposed to hepatitis $\mathrm{C}$ virus $(\mathrm{HCV})^{67}$ from the use of non-inactivated replacement factor concentrates from pooled human blood until 1986, when effective heat treatment was introduced. The presence of HCV in patients with haemophilia has been reported to be at least $70 \% .{ }^{68} \mathrm{~A}$ similar situation existed with human immunodeficiency virus (HIV), followed by possible risk from blood products contaminated with vCJD. As many as 4,000 people in the UK, mainly with haemophilia, have been warned by the CJD Incidents Panel that they may be at risk from blood products received before 1999. Viral inactivation of plasma-derived factor concentrates was introduced in the mid-1980s and the use of recombinant (non-human derived) factor concentrates started in the early 1990s. To further avoid viral contamination, wherever possible, treatments that avoid the use of blood or blood products have been developed. These measures have reduced, if not removed, the risk of viral or prion transmission with these products. ${ }^{59}$

\section{Modification of dental treatment}

Recent guidelines produced by the World Haemophilia Federation ${ }^{59}$ conclude that most patients with haemophilia can receive the majority of their routine dental care in the primary care setting following the principles set out in Table $11 .{ }^{53,59}$ The goal of treatment is to minimise the challenge to the patient by restoring the haemostatic system to acceptable levels and maintaining haemostasis by local and adjunctive methods. ${ }^{69}$

Patients with CBD are often anxious about dental treatment on several fronts - the complexity or unpleasantness of treatment itself, unease about disclosing a medical history which may attract a degree of stigma, and concern about dentists' understanding of their condition and its management. ${ }^{62}$ Consequently, people may avoid dental treatment until they have a problem and extensive treatment needs ${ }^{53}$ and this may account for the higher incidence of dental caries and periodontal disease in patients with bleeding disorders. ${ }^{70}$

Spontaneous bleeding has been reported in patients with haemophilia 
under conditions of emotional stress and it has been advocated that the dental professional should consider the possibility of bleeding as a result of the stress associated with dental treatment. ${ }^{58}$ Conscious sedation using midazolam can be used to control anxiety and possibly prevent haemorrhage, provided care is taken during venepuncture to avoid a haematoma. For this reason, where possible, the dorsum of the hand is preferred to the ante-cubital fossa. ${ }^{22}$

Precautions need to be taken before invasive dental procedures likely to cause haemorrhage, such as administration of an inferior dental block, extractions, implants, or periodontal surgery. These procedures need a factor level between 50-75\%. As coagulant therapy prior to dental treatment raises the factor levels to near normal, with this cover people can receive dental treatment in primary care. ${ }^{53}$ The half-life of coagulation factors needs to be considered when planning treatment. Factor VIII has a half-life of only 10-12 hours and dental treatment needs to be carried out on the day of cover. Although preferable, it is rarely possible for extensive treatment to be completed in one visit. However, treatment should be organised to minimise the number of factor replacement sessions and thus the likelihood of antibody development. Factor IX has a longer half-life, allowing dental treatment to be carried out on consecutive days under a single dose of replacement therapy. ${ }^{71}$

Effective alternatives to factor replacement prior to dental treatment for people with mild haemophilia and some forms of vWD include the use of desmopressin (DDAVP) and tranexamic acid (Cyclokapron). The latter can be used systemically in a dose of $1 \mathrm{~g}$ orally four times a day, or topically as a mouthwash four times a day for up to seven days post-operatively. It can be prescribed for hospital use but is not readily available in the community, although patients may be able to obtain it from their haematology clinic for dental use. Lee et al. ${ }^{67}$ using a double-blind cross-over randomised trial, showed that tranexamic mouthwash after dental scaling was as effective as factor replacement therapy beforehand in controlling gingival haemorrhage for people with haemophilia ${ }^{66}$ For all procedures, whether the

\begin{tabular}{|c|c|}
\hline Dental procedure & Considerations \\
\hline Care of soft tissues & $\begin{array}{l}\text { Regular use of chlorhexidine mouthwash to reduce gingival inflammation } \\
\text { Minimise accidental damage during treatment - apply soft paraffin wax, } \\
\text { use moistened cotton wool rolls to avoid adherence to the mucosa }\end{array}$ \\
\hline Restorative treatment & $\begin{array}{l}\text { Coagulant cover unnecessary } \\
\text { Take care to protect the mucosa with impressions, X-ray films, } \\
\text { matrix bands, etc }\end{array}$ \\
\hline Subgingival restorations & $\begin{array}{l}\text { Use local haemostatic agents such as epinephrine on gingival retraction } \\
\text { cord, or topical tranexamic acid solution }\end{array}$ \\
\hline Endodontics & $\begin{array}{l}\text { Avoid instrumentation beyond the apex by careful estimation of working } \\
\text { length using apex locator and radiographs }\end{array}$ \\
\hline Endodontics & $\begin{array}{l}\text { Haemorrhage in the canal due to pulp remnants requires irrigation with } \\
\text { sodium hypochlorite and calcium hydroxide paste to control bleeding }\end{array}$ \\
\hline Use of rubber dam & $\begin{array}{l}\text { Take care to prevent trauma } \\
\text { Avoid placing clasps on gingivae }\end{array}$ \\
\hline $\begin{array}{l}\text { Use of high speed aspiration } \\
\text { and saliva ejectors }\end{array}$ & $\begin{array}{l}\text { Place a gauze square in the floor of the mouth to avoid trauma and } \\
\text { haematoma formation }\end{array}$ \\
\hline Denture provision & $\begin{array}{l}\text { Care with fitting } \\
\text { Regular review to ensure fit } \\
\text { Judicious use of soft or resilient lining materials }\end{array}$ \\
\hline $\begin{array}{l}\text { Orthodontic treatment } \\
\text { - fixed and removable }\end{array}$ & $\begin{array}{l}\text { Additional preventive advice } \\
\text { Additional oral hygiene advice } \\
\text { Use of soft red wax on cribs, etc to prevent soft tissue damage }\end{array}$ \\
\hline Routine scaling & $\begin{array}{l}\text { Post-operative antifibrinolytic mouthwash, eg tranexamic } \\
\text { acid mouthwash }\end{array}$ \\
\hline $\begin{array}{l}\text { Periodontal surgery } \\
\text { and deep root planing }\end{array}$ & $\begin{array}{l}\text { Requires good oral hygiene } \\
\text { Requires factor cover }\end{array}$ \\
\hline Local anaesthesia & $\begin{array}{l}\text { Avoid inferior dental blocks and lingual infiltration } \\
\text { Use agents containing vasoconstrictors }\end{array}$ \\
\hline
\end{tabular}

patient has received prophylactic coagulant cover or not, care should be taken to minimise trauma. ${ }^{5,53,59,60}$ Table 12 sets out some of the considerations required. Healthy periodontal tissue is essential to prevent gingival bleeding, which can be especially troublesome in patients with vWD, during dental treatment.

There are no restrictions regarding the type of local anaesthetic agent used and those with vasoconstrictors may provide additional local haemostasis. A buccal infiltration can be used without any factor replacement, but an inferior dental block must only be given after raising clotting factor levels by appropriate replacement therapy as there is a risk of bleeding into the muscles, along with potential airway compromise due to a haematoma in the retromolar or pterygoid space. Similarly, the use of lingual infiltration should be avoided without factor cover as it too carries the risk of a significant haematoma. Intraligamental, papillary or intra-osseous techniques should be considered as alternatives. Buccal infiltration of articaine has been reported to successfully anaesthetise mandibular molars. ${ }^{72}$ If sufficient pulpal analgesia is provided, this may also preclude the need for factor replacement.

Local measures are important to minimise the risk of post-operative bleeding. Any surgery should be carried out with minimal trauma and suturing is desirable to stabilise gum flaps using the minimum number of sutures. ${ }^{5}$ Use of both non-resorbable and resorbable sutures has been advocated. ${ }^{8,57}$ Topical haemostatic agents such as oxidised cellulose soaked in tranexamic acid provide rapid haemostasis. Careful post-operative instructions should include a soft or liquidised diet and the use of tranexamic 
acid either as a mouthwash or a swish and swallow regime. ${ }^{5,59}$

Despite all measures, post-operative haemorrhage may still occur occasionally following surgery. Patients should be warned of the possibility of haemorrhage, usually 7-12 hours post-operatively, and instructed to contact their haematology unit or haemophilia centre in the first instance, where they might consider further clotting factor infusion. The wound should be examined for signs of a tear or trauma and local measures should be used as previously described. Furthermore, the patient should be instructed to bite on gauze soaked in tranexamic acid for at least 10 minutes. ${ }^{59}$

If prescribing for patients with congenital bleeding disorders, there are no contra-indications to any of the antibiotics from the dental formulary of the British national formulary, from which dentists may prescribe. ${ }^{53}$ However, all bleeding tendencies can be aggravated by the use of aspirin or other NSAIDs. Dental pain can usually be controlled with a minor analgesic and better choices are paracetamol or codeine-based products.

Careful history taking and treatment planning along with providing the patient with appropriate information allows most safety issues in the dental setting to be pre-empted and either avoided or dealt with in a structured way. Unfortunately, it is not possible to mitigate all dental emergencies, and appropriate staff training that is regularly updated is essential to prepare the dental team for coping safely with the unexpected event.

1. Fiske J, Boyle C. Epilepsy and dental care. Dent Update 2002; 4: 180-187.

2. Heaney D, Macdonald B, Everitt A et al. Socioeconomic variation in incidence of epilepsy; prospective community based study in South East England. BMJ 2002; 325: 1013-1016.

3. Sanders B, Weddell J, Dodge N. Managing patients who have seizure disorders; dental and medica issues. J Am Dent Assoc 1995: 126: 1641-1647.

4. Scully C, Cawson R. Neurological disorders. In Medical problems in dentistry. Chapter 17. Oxford: Wright, 1999.

5. Scully C, Dios P D, Kumar N. Special care in dentistry: handbook of oral healthcare. pp 171-177. Edinburgh: Churchill Livingstone, 2007.

6. Sander J, Hart Y. Epilepsy: questions and answers. pp 43-51. Hampshire: Merit Publishing International, 1999.

7. British National Formulary 55. London: BMJ Publishing Group and RPS Publishing, 2008.

8. Sander J W. The incidence and prevalence of epilepsy. In Sander J W. Walker M C, Smalls J E (eds) Epilepsy 2007: from cell to community, a practice guide to epilepsy. pp 1-6. Chalfont: National Society for Epilepsy and International League Against Epilepsy, 2007. www.e-epilepsy.org.uk

9. Prasad V N, Chawla H S, Goyal A, Gauba K, Singhi P. Incidence of phenytoin induced gingival overgrowth in epileptic children: a six month evaluation. J Indian Soc Pedod Prev Dent 2002: 20: 73-80.

10. Stinnett E, Rodu B, Grizzle W. New development in understanding phenytoin induced gingival hyperplasia. J Am Dent Assoc 1987; 114: 814-816.

11. Güncü G N, Caglayan F, Dinçel A, Bozkurt A, Saygi $S$, Karabulut E. Plasma and gingival crevicular fluid phenytoin concentrations as risk factors for gingival overgrowth. J Periodontol 2006; 77: 2005-2010.

12. Lafzi A, Farahani R, Shoja M. Phenobarbitalinduced gingival hyperplasia. J Contemp Dent Pract 2007; 8: 50-56.

13. Majola M P, McFadyen M L, Connolly C, Nair Y $P$, Govender M, Laher M H. Factors influencing phenytoin-induced gingival enlargement. J Clin Periodontol 2000; 27: 506-512.

14. Seymour R, Ellis J, Thomason J. Risk factors for drug-induced gingival overgrowth. J Clin Periodontol 2000; 27: 217-223.

15. Dahllof G, Axio E, Modeer T. Regression of phenytoin-induced ginigval overgrowth after withdrawl of medication. Swed Dent J 1991; 15: 139-143.

16. Pick L, Bauer J. Dentistry and epilepsy. Nervenarzt 2001; 72: 946-949.

17. Dougall A, Fiske J. Access to special care dentistry, part 4. Education. Br Dent J 2008; 205: 119-130.

18. Mackie I. Doctors must take the lead by prescribing sugar free medicines whenever possible. BMJ 1995; 311: 141-142

19. Buck D, Baker G, Jacoby A, Smith D, Chadwick D. Patients' experiences of injury as a result of epilepsy. Epilepsia 1997; 38: 439-444.

20. Radnai M, Szontágh E, Fazekas A. Prosthetic rehabilitation of an epilepsy patient with dental implants. Case report. Fogorv Sz 2006 99: 121-124.

21. Rood J. Local anaesthesia and the medically compromised patient. Dent Update 1991; 18: 330-334.

22. Dougall A. Sedation and special care dentistry. Dental Sedation Teachers Group Annual Meeting, Birmingham, 2007

23. Robb N, Hargrave S. Tolerance to intravenous midazolam as a result of oral benzodiazepine therapy, a potential problem for the provision of conscious sedation in dentistry. Anesth Pain Control Dent 1993; 2: 94-97.

24. Manley G, Skelly M. The use of sedation in the treatment of people with disability. In Nunn J (ed) Disability and oral care. Chapter 10. London: FDI World Press, 2000

25. Hickey K, Martin D, Chuidian F. Propofol-induced seizure-like phenomena. J Emerg Med 2005; 4: $447-449$

26. National Institute for Clinical Excellence. The epilepsies. The diagnosis and management of the epilepsies in adults and children in primary and secondary care. London: NICE, 2004. Clinical guideline 20. www.nice.org.uk/guidance

27. Walker M C. Treatment of non-convulsive status epilepticus. In Sander J W, Walker M C, Smalls J E (eds) Epilepsy 2007: from cell to community, a practice guide to epilepsy. pp 317-322. Chalfont: National Society for Epilepsy and International League Against Epilepsy, 2007. www.e-epilepsy.org.uk

28. Heafield M TE. Managing status epilepticus. BMJ 2000; 320: 953-954.

29. Behrman A J, Howarth M. Latex allergy. eMedicine online article, http://www.emedicine.com/emerg/ topic814.htm (accessed 7 July 2008)

30. Latex Allergy Support Group website. 2007. www.lasg.co.uk

31. Longman L. Rubber trouble. Irish Society for Disability and Oral Health Summer Conference 2007, Tullamore, Ireland.

32. Clark A. The provision of dental care for patients with natural rubber latex allergy: are patients able to obtain safe care? Br Dent J 2004; 197: 749-752.

33. Faculty of General Dental Practice (UK). Guidance for the management of natural rubber latex allergy in dental patients and dental healthcare workers. London: FGDP(UK), 2004.

34. Field $E$, Longman $L$, Sharkawi $M$, Perrin L, Davies $M$. The dental management of patients with natura rubber latex allergy. Br Dent J 1998; 185: 65-69.

35. Field $E$, Fay $M$. Issues of latex safety in dentistry. BrDent J 1995; 179: 247-253.

36. Kelly K, Pearson M, Kurup V. Anaphalactic reactions in patients with spina bifida during general anaesthesia. J Allergy Clin Immunol 1994; 93: 813-816.

37. Kamm M. Faecal incontinence. BMJ 1998 316: $528-532$

38. Resuscitation Council UK. Emergency treatment of anaphylactic reactions. Guidelines for healthcare providers. London: Resuscitation Council UK, 2008. www.resus.org.uk/pages/reaction.pdf

39. Resuscitation Council UK. Frequently asked questions on 'Emergency treatment of anaphylactic reactions. Guidance for healthcare providers' London: Resuscitation Council UK, 2008. www. resus.org.uk/pages/faqAna.htm

40. Ruggiero S. Osteonecrosis of the jaws and bisphosphonate therapy. J Dent Res 2007; 86: 1013-1021.

41. Woo S-B, Hellstein J W, Kalmar J R. Narrative [corrected] review: bisphosphonates and osteonecrosis of the jaws. Ann Intern Med 2006; 144: 753-761.

42. American Dental Association. Dental management of patients receiving oral bisphosphonate therapy - expert panel recommendations. J Am Dent Assoc 2006: 137: 1144-1150.

43. World Health Organization. WHO scientific group on the assessment of osteoporosis at the primary health care level. Summary meeting report. Geneva: World Health Organization, 2007. http:// www.who.int/chp/topics/Osteoporosis.pdf

44. National Osteoporosis Society website. www.nos. org.uk (accessed 8 July 2008).

45. McMahon R E, Bouquot J E, Glueck C J et al. Staging bisphosphonate-related osteonecrosis of the jaw should include early stages of disease. J Oral Maxillofac Surg 2007; 65: 1899-1900.

46. Migliorati C, Casiglia J, Epstein J, Jacobsen P, Siege M. Managing the care of patients with bisphosphonate associated osteonecrosis. J Am Dent Assoc 2005; 136: 1658-1668.

47. Anon. Bisphosphonate therapy and osteonecrosis of the jaws. Contemporary Oral Hygiene 2006 December: http://www.contemporaryoralhygieneonline.com/issues/articles/2006-12_10.asp

48. Cramer J, Lynch N, Gaudin A, Walker M, Cowell W. The effect of dosing frequency on compliance and persistence with bisphosphonate therapy in post-menopausal women in the United States, United Kingdom and France. Clin Ther 2006; 10: 1686-1694.

49. Barker K, Rogers S. Bisphosphonate-associated osteonecrosis of the jaws - a guide for the general dental practitioner. Dent Update 2006; 33: $270-272$.

50. American Association of Endodontists. AAE position statement. Endodontic implications of bisphosphonate-associated osteonecrosis of the jaws. Chicago: American Association of Endodontists, 2006. http://www.aae.org/dentalpro/EducationalResources/guidelines.htm

51. Kearns G. BRONJ - the bisphosphonate story for the ageing population. Irish Society for Disability and Oral Health Winter Meeting, Dublin. November 2007.

52. Lane N. Long-term effects of treatment with alendronate for patients with osteoporosis. Nat Clin Pract Rheumatol 2007; 3: 426-427.

53. Rafique $S$. Managing patients with bleeding disorders. In Fiske J, Dickinson C, Boyle C, Rafique S, Burke M Special care dentistry. pp 103-114 London: Quintessence Publishing, 2007.

54. Lockhart P B, Gibson J, Pond S H, Leitch J. Dental management considerations for the patient with an acquired coagulopathy. Part 1: coagulopathies from systemic disease. Br Dent J 2003; 195: 439-445.

55. Randall C (ed). Surgical management of the 
primary care dental patient on antiplatelet medication. Liverpool: North West Medicines Information Centre, 2007. http://www.druginfozone.nhs.uk/ Record\%20Viewing/viewRecord.aspx?id $=582288$

56. Randall C (ed). Surgical management of the primary care dental patient on warfarin. Liverpool: North West Medicines Information Centre, 2007. http://www.druginfozone.nhs.uk/ Record\%20Viewing/viewRecord. aspx?id=582287

57. Richards S. Guidelines for the management of patients who are taking oral anticoagulants and who require dental surgery. Evid Based Dent 2008; 9: 5-6.

58. Gomez-Moreno G, Cutando-Soriano A, Arana C, Scully C. Hereditary blood coagulation disorders: management and dental treatment. J Dent Res 2005; 84: 978-985.

59. Brewer A, Correa M. Guidelines for dental treat ment of patients with inherited bleeding disorders. Montréal: World Federation of Hemophilia, 2006. Treatment of Hemophilia Monograph no. 40.

60. Brewer A, Roebuck E, Donachie M et al. The dental management of adult patients with haemophilia and other congenital bleeding disorders. Hemo- philia 2003: 9: 673-677.

61. Stubbs M, Lloyd J. A protocol for the dental management of von Willebrand's disease, haemophilia A and haemophilia B. Aust Dent J 2001; 46: 37-40.

62. Fiske J, Pitt Ford H, Savidge G, Smith M. The expressed dental needs of patients attending a haemophilia reference centre. J Disabil Oral Health 2000; $1: 20-25$

63. Harrington B. Primary care of patients with haemophilia. Hemophilia 2000; 6(Suppl): 7-12.

64. White G C 2nd, Rosendaal F, Aledort L M et al. Definitions in hemophilia. Recommendation of the scientific subcommittee on factor VIII and factor IX of the scientific and standardization committee of the International Society on Thrombosis and Haemostasis. Thromb Haemost 2001; 85: 560.

65. The Haemophilia Society. Information fact sheet. von Willebrand's: general information. London: The Haemophilia Society, 2003. http://www.haemophilia.org.uk/uploads/vwillebrandsgeneral.pdf

66. Lee A, Boyle C, Savidge G, Fiske J. Effectiveness in controlling haemorrhage after dental scaling in people with haemophilia by using tranexamic acid mouthwash. Br Dent J 2005; 198: 33-38.
67. Fried M. Management of hepatitis $C$ in the haemophilia patient. Am J Med 1999; 107: 855-895.

68. Eyster M E, Diamondstone LS, Lien J M, Ehmann W C, Quan S, Goedert J J. Natural history of hepatitis $C$ virus infection in multitransfused hemophiliacs: effect of coinfection with human immunodeficiency virus. The Multicenter Hemophilia Cohort Study. J Acquir Immune Defic Syndr 1993; 6: 602-610.

69. Gupta A, Epstein J, Cabay R. Bleeding disorders of importance in dental care and related patient management. J Can Dent Assoc 2007; 73: 77-83.

70. Meechan J G, Greenwood M. General medicine and surgery for dental practitioners. Part 9: haematology and patients with bleeding problems. Br Dent J 2003; 195: 305-310.

71. Morfini $M$, Lee $M$, Messori A. The design and analysis of half-life and recovery studies for factor VIII and factor IX. Thromb Haemost 1991; 66: 384-386.

72. Robertson D, Nusstein J, Reader A, Beck M, McCartney $M$. The anesthetic efficacy of articaine in buccal infiltration of mandibular posterior teeth. J Am Dent Assoc 2007; 138: 1104-1112. 